\title{
Effect of Variable Length Intake Manifold on Performance of IC Engine
}

\author{
Bayas Jagadishsingh G.* and N.P. Jadhav \\ Department of Mechanical Engineering, SAE Kondhwa (Bk), SPPU Pune, India \\ Accepted 15 June 2016, Available online 20 June 2016, Special Issue-5 (June 2016)
}

\begin{abstract}
Engine power \& torque are greatly affected by degree to which cylinders are charged \& the geometric aspects of intake manifold. Conventional intake manifolds have fixed length \& geometry which is optimized for specific engine speed which is equal to maximum toque rpm of specified engine. Current work aims at studying \& analyzing the effect of variable intake length on performance of single cylinder, four stroke IC engine. This will be analyzed with the help of engine simulation software \& experimentation on an actual engine. Intake manifold with different intake lengths mounted on engine under test \& the results are analyzed. The volumetric efficiency of engine found to be increased by varying the intake length. Engine toque \& brake power observed to be improved at different engine speeds with the help of variable inertia charging system.
\end{abstract}

Keywords: Inertia charging, intake tuning, Plenum, VIL, 1-D CFD, Engine Simulation.

\section{Introduction}

Early Engine charging system greatly affects the engines performance which is a well-known fact. Various attempts were made to improve engines volumetric efficiency some of which proved extremely important e.g. supercharging \& turbocharging. In case of naturally aspirated engines volumetric efficiency is still low which is in the range of $75-80 \%$. Another problem with intake system is that in conventional engines it is optimized for a specific speed at which it gives maximum torque. Studies showed that longer intake manifolds give peak torque at low engine rpm \& shorter engine manifolds gives peak torque at higher engine rpm. Conventional engines have intake manifolds which are compromised to get benefit of both.

Intake system comprises of various complicated paths such as air cleaner, intake pipe, throttle body, plenum \& runners/resonators to each cylinder. Air flows through all these parts \& finally enters in to engine cylinder. The main parts of the intake system are plenum, \& runners. Overall length including runner \& plenum \& volume of plenum mainly affects the torque characteristics of engine. Important design criteria for designing an intake manifold are: low air flow resistance, good distribution of air \& fuel between cylinders, runner \& branch lengths that take advantage of ram \& tuning effects, sufficient but not enough excessive heat to ensure vaporization of fuel in case of carbureted or throttle body injected engines.

\subsection{Problem Definition}

The output and torque of an engine have the greatest effect on the engine's character. These, in turn, are greatly affected by the degree to which the cylinder is filled and the geometric form of the intake tract. High torque requires an intake manifold with geometry different to one for high power output. A medium intake manifold length with a medium diameter represents a compromise but it results in the lower torque \& power at very low \& high speeds which ultimately results into degraded performance \& less fuel economy. Variable intake manifold poses an ideal alternative to solve this problem.

\subsection{Aim}

Current project work is basically aimed at analyzing the effect of intake manifold length variation on performance of IC engine. Intake manifold of varying intake length for different engine speed is to be mounted on existing engine \& its effect to be analyzed. Virtual simulation will be done on engine simulation software to verify the theoretical calculations of intake length.

\subsection{Objectives}

- To study the effect of variable inertia charging system on performance of an engine \& calculation of intake length by theoretical methods.

- To test engine performance by mounting intake of different lengths accordance with the engine speed. 
- To compare the experimental \& 1-D engine simulation results.

\subsection{Literature Review}

M. A. Ceviz conducted experiments to study effects of intake plenum volume variation on engine performance and emission. Brake and indicated engine performance characteristics, coefficient of variation in indicated mean effective pressure (covimep) were taken into account. He concluded that the engine performance can be increased by using intake plenum volume that is continuously variable. M.A. Ceviz and M. Akin investigated the effects of intake plenum volume on the performance of a spark-ignited engine with electronic fuel injector. Si engines with multipoint fuel injection system showed better characteristics than carbureted one. The results showed that the variation in the plenum length causes an improvement in fuel consumption at high load and low engine speeds. [2] Research work done by Jensen Samuel et. al. in their research work entitled Effect of Variable Length Intake Manifold on a Turbocharged Multi-Cylinder Diesel Engine "'" they have validated major engine parameters with 1000hp V46-6 turbo diesel engine and the deviations were found to be less than $5 \%$ of the experimental data. Two different engine configurations have been studied in this work - a single cylinder NA engine and a 12 cylinder turbocharged engine. Thermodynamic simulations show that in both cases, the volumetric efficiency can be improved by the use of a variable length intake manifold.

\section{Methodology}

Inlet manifold generally experiences two kind of pressure waves one being compression \& other is suction wave. Intake manifold can be tuned in such a way that the volumetric efficiency of more than $100 \%$ can be achieved. Thus improvement in the torque output and power of the engine is possible. Air flowing through the intake manifold runner, past the intake valve and into the cylinder flows alike until the intake valve closes. After the closure of valve air strikes on the closed valve \& high pressure wave is created. This is the compression wave \& travels back and forth along the closed intake runner length. Tuning the intake manifold is nothing but making the compression wave come back at the inlet valve exactly when it opens. This compression wave then rushes into the cylinder to the feel it at values more than that of normal one \& maximum volumetric efficiency is achieved. The effect is termed as Ram effect charging \& length of intake manifold to achieve that Ram effect can be predicted by Chryslers Ram Theory.

Another wave is the rarefaction or suction wave, it generates when the inlet valve opens \& the vacuum of the cylinder is exposed to the inlet manifold. This low pressure when travels from inlet valve opening to the other end of intake manifold i.e. To the atmosphere in case of single cylinder engine \& gets reflected as pressure wave. The high pressure wave then generated travels back towards inlet valve. The timing of arrival of this reflected high pressure wave can be tuned with opening of the intake valve by appropriately designing the inlet manifold. Tuning of the intake manifold in this way increases the local density of the air at the inlet. In cylinder pressure get increased at ivc causing maximum possible volumetric efficiency.

\subsection{Chrysler Ram Theory}

Air flowing inside the intake manifold runner, past the intake valve and into the cylinder flows alike until the intake valve closes. After the closure of valve air strikes on the closed valve \& high pressure wave is created. This high pressure wave oscillates in the inlet duct until the inlet valve opens for next stroke. The time after which inlet valve opens again if matches to the time of arrival of high pressure wave of air at inlet then Ram effect occurs causing highest possible air pressure at IVC. Tuning corresponds to adjusting the length of intake runner so that this pressure wave reaches exactly at the time when the inlet valve opens. This effect is also called as inertial ram effect and length is decided by Chryslers Ram Theory.

Pressure wave travels at the speed of sound. At the normal atmospheric conditions speed of sound is around 343 meter per second. For our engine in consideration (NA Diesel, Bore-87.5mm, stroke$110 \mathrm{~mm}$ ) inlet valve remains open for $256^{\circ}$ of rotation. The engine rotates two times $\left(720^{\circ}\right)$ for the intake to open once.

\section{Therefore}

$720^{\circ}-220^{\circ}=500^{\circ}$ of crank rotation our intake valve remains closed.

At let's say $1500 \mathrm{rpm}$,

$1500 / 60=25 \mathrm{rev} / \mathrm{sec}$

$25 \mathrm{rev} / \mathrm{sec}^{*} 360^{\circ} / \mathrm{rev}=9,000 /$ seconds

$500^{\circ} / 9,000=0.05556$ seconds for compression wave to travel back to the intake valve when it opens again.

0.05556 seconds $* 343 \mathrm{~m} / \mathrm{s}=19.05 \mathrm{~m}$

This is the distance which wave travels at speed of sound. Now wave has to travel back to the intake valve so intake length becomes half because wave travels up \& down the intake which is $9.52 \mathrm{~m}$. installing that much long intake is practically difficult so integer multiple (3, $6,12, \ldots)$ of that length can be used without much affecting the benefit of Ram effect. So by taking integer multiple of 6 we get intake length of $1.58 \mathrm{~m}$. Similar calculations can be done to calculate intake length for getting maximum volumetric efficiency at different engine speeds.

Same relationship in between the engine speed \& pipe length for tuning conditions can be obtained from following equation; 
$\mathrm{N}=\mathrm{c} \Delta \theta / 12 \mathrm{~L}$

$\Delta \theta$ is the period in which wave travels in crank angle degrees for tuned conditions. For an $i^{\text {th }}$ order pulse the equation becomes:

$\mathrm{N}=\frac{\mathrm{c} \Delta \theta}{6(2+4(\mathrm{i}-1)) \mathrm{L}}$

Where $\mathrm{i}$ is the order of the pulse. Fist order is said when the reflected wave travels back to intake valve only one. For other higher orders the wave travels multiple times until next favorable wave comes again.

The wave travels with the progression of $2,6,10,14, \ldots,(2+4(i-1))$ where $i$ is the number of the pulse order. The strength of the wave decreases with increasing pulse order thus, for practical purposes, only the first three pulse orders are considered.

\subsection{Helmholtz Resonator Theory}

This considers the volume of air inside the intake runner as spring which compresses \& expands upon application of force to it. The air inside combustion chamber is considered as mass. Effective volume is considered to be the cylinder volume at the mid stroke. Following figure shows the arrangement.

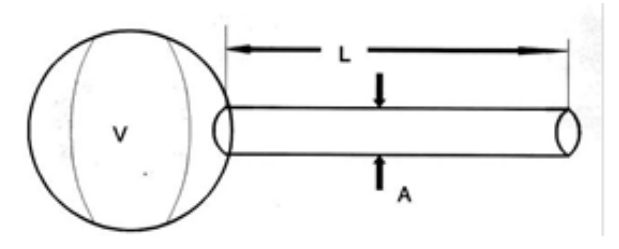

Fig. 1 Helmholtz resonator arrangement

$V e f f=V \mathrm{~d} / 2+V C L$

Where Vd is the swept volume and VCL is clearance volume. Now writing by manipulating compression ration \& swept volume we get final equation as:

$$
\begin{array}{lc}
\mathrm{CR}=\frac{\left(\mathrm{V}_{\mathrm{s}}+\mathrm{V}_{\mathrm{CL}}\right)}{\mathrm{V}_{\mathrm{CL}}} & \mathrm{V}_{\mathrm{CL}}=\frac{\mathrm{V}_{\mathrm{s}}}{\mathrm{CR}-1} \\
\mathrm{~V}_{\text {eff }}=\frac{\mathrm{V}_{\mathrm{D}}}{2}+\frac{\mathrm{V}_{\mathrm{D}}}{\mathrm{CR}}-1 & \mathrm{~V}_{\text {eff }}=\frac{V_{D}(C R-1)+2 V_{D}}{2(C R-1)} \\
\mathrm{V}_{\text {eff }}=\frac{\mathrm{V}_{\mathrm{D}}(\mathrm{CR}+1)}{2(\mathrm{CR}-1)} & \\
\mathrm{N}=\frac{13.5 \mathrm{c}}{\mathrm{k}} \sqrt{\frac{\mathrm{A}}{\mathrm{LVd}}} \sqrt{\frac{\mathrm{CR}-1}{\mathrm{CR}+1}} &
\end{array}
$$

\section{Engine \& Computation Model}

\subsection{Details of 1-D CFD code}

Commercially available 1-D CFD code Lotus engine simulation is used for predicting the effect of intake manifold length on engine performance. Lotus engine simulation package is provided at free of cost for the academic institutions by Leosoft organization (UK). It is 1-D CFD code which commercially used for engine simulations during engine design \& development process \& shares same platform as Ricardo-Wave, GTPower, AVL Boost \& etc. engine simulation soft wares.

The tool has been developed by experts at Lotus Cars by extensive experience of applying performance simulation to engine design projects. The tool can be used to simulate the performance of two and four stroke, gasoline and diesel, naturally aspirated or supercharged and turbocharged engines.

Lotus engine simulation models the gas dynamics in the engine manifolds and enables the complex operating modes used in modern engines to be simulated.

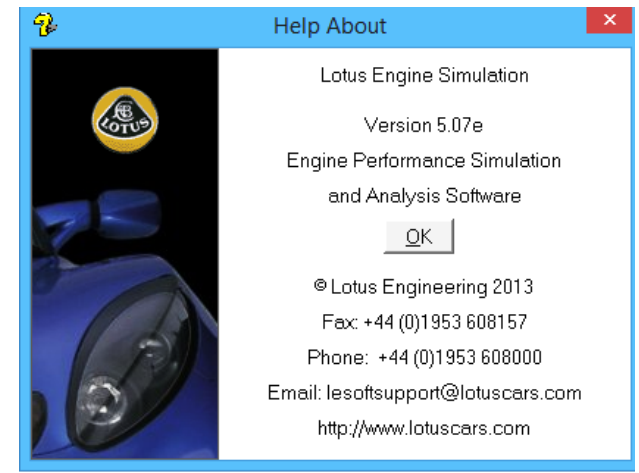

Fig. 2 Details Lotus Engine Simulation software

\subsection{Engine set-up used for Experimentation}

Single cylinder 4-S CI engine is used for experimentation \& computation model. 1-D Engine simulation model is calibrated using the cylinder P- $\theta$ data from the same engine. Engine geometry such as bore, stroke, valve timings \& lift, intake pipe length, etc. was reproduced as closely as possible in the computational model.

Table 1 Engine Specifications under Study

\begin{tabular}{|c|c|}
\hline Make \& Model & Kirloskar TV1, Single Cylinder 4S CI \\
\hline Bore * Stroke & $87.5^{*} 110 \mathrm{~mm}$ \\
\hline Swept Volume & $661 \mathrm{cc}$ \\
\hline Max Power & $5.2 \mathrm{KW}$ \\
\hline CR & 17 \\
\hline IVO, IVC & $4.5^{\circ}, 35.5^{\circ}$ \\
EVO, EVC & $35.5^{\circ}, 4.5^{\circ}$ \\
\hline
\end{tabular}

Length of the intake manifold is changed for speed range of 1200-2000 rpm by keeping all other parameters constant. Following table shows how length is varied for different speeds.

\subsection{Length calculation by using empirical relationships}

Length of the intake manifold is calculated for speed range of 1200-2000 rpm by using Chrysler Ram theory \& Helmholtz Resonator theory respectively using the equation (2) \& (4). Following table shows how length is varies for different speeds. 
The predicted lengths for obtaining benefit of peak volumetric efficiency at lower speed range using Ram theory are comparatively shorter than those predicted by Helmholtz resonator Theory.

Table 2 Tuned Intake Lengths for Different Engine Speeds (in meters)

\begin{tabular}{|c|c|c|}
\hline RPM & Ram Theory & Helmholtz Theory \\
\hline 2000 & 1.2 & 0.98 \\
\hline 1800 & 1.32 & 1.21 \\
\hline 1600 & 1.49 & 1.53 \\
\hline 1400 & 1.7 & 2 \\
\hline 1200 & 1.98 & 2.72 \\
\hline
\end{tabular}

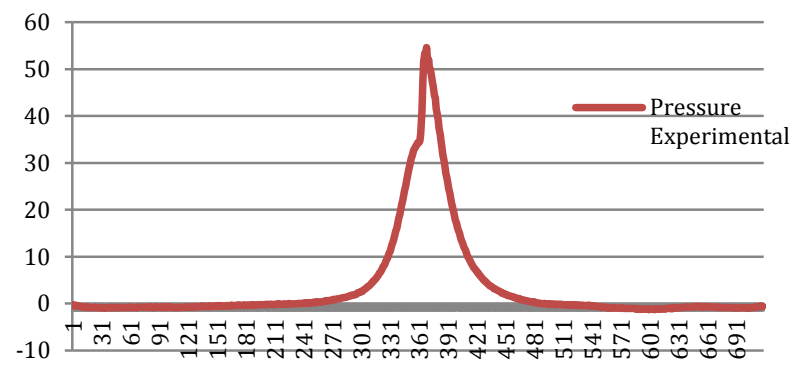

Crank Angle $\theta$

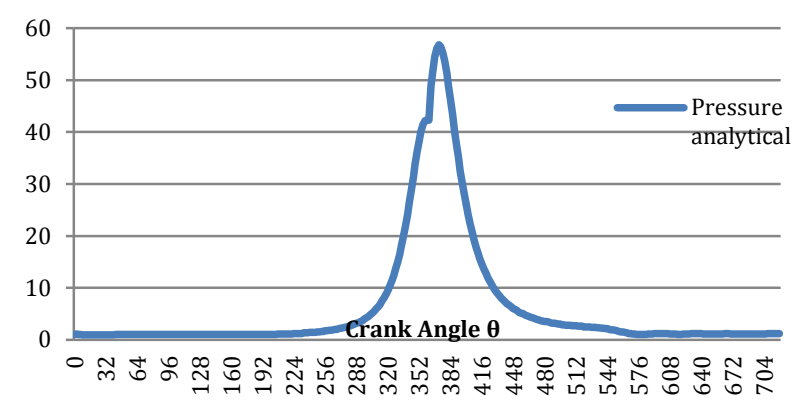

Fig. 2 Cylinder pressure vs Crank angle data measured versus simulated.

Above figure shows the comparison of the cylinder pressure data obtained using 1-D engine simulation \& experimentation. The pressure developed in engine actually \& simulated is in better agreement. Therefore from above P- $\theta$ graph it can be considered that the engine simulation predicts the engine performance in good agreement with the experimental engine.

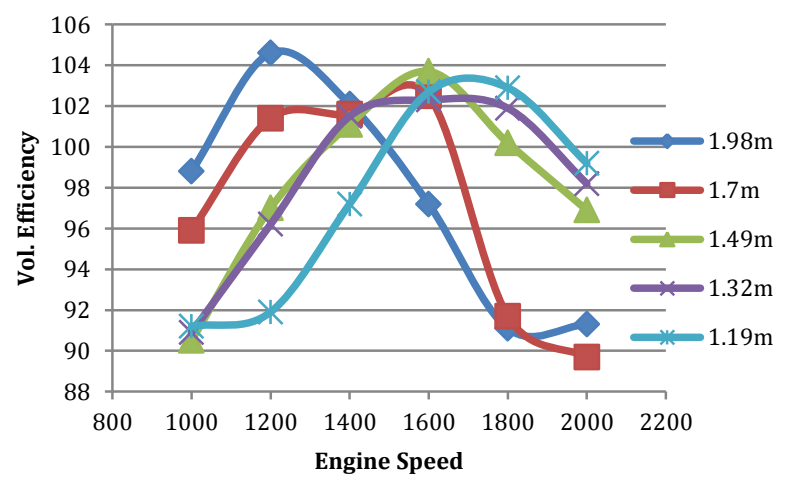

Fig. 3 Volumetric efficiency versus engine speeds for varying intake length (1-D Simulation)
Graph above shows the volumetric efficiency values for different intake lengths. Intake lengths calculated by theoretical methods proves quite matching with the peak volumetric efficiency values by engine simulation. Here Ram theory is only used to predict peak volumetric efficiency values since Helmholtz theory predicted quite longer intake lengths for lower rpm band \& some of the authors previously worked on the concept found Ram Theory more effective in intake tuning.

Following figure shows the volumetric efficiency gain by using intake of different lengths for various operating speeds.

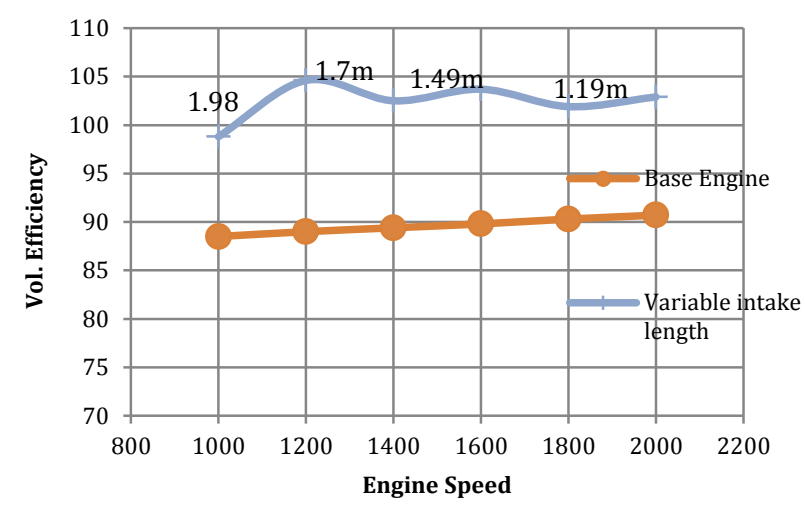

Fig. 4 Volumetric efficiency Gain by varying intake length (1-D Simulation)

As the volumetric efficiency increases similarly torque benefits are obtained using the intake length variation at different engine speeds. The graph obtained by simulation is shown below.

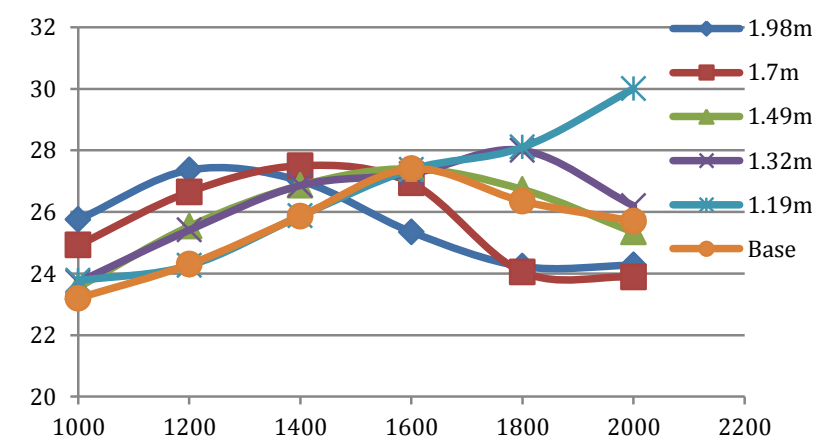

Fig. 5 Torque benefit at low \& high engine speeds by varying intake length (1-D Simulation)

\section{Experimentation \& Results}

Existing engine has intake manifold which has runner length of around $250 \mathrm{~mm}$ with intake diameter of $45 \mathrm{~mm}$. Firstly test was carried out using existing intake manifold \& volumetric efficiency values were observed. Then the intake manifold length was changed as per the calculations done by using empirical relationships. Engine performance parameters observed mainly were the volumetric efficiency, brake torque \& brake power. 
For experimentation the air box of current engine is connected with another air box which was made using Plastic material. Reason behind using secondary air box was that the intake runner length variation was not possible with existing air box (plenum) since it was fixed at one place. The secondary air box/plenum then connected to engine using the intake runners of different lengths as per the calculations from Ram theory \& then engine is tested to analyze its performance.

\subsection{Base Engine Performance \& its comparison with simulated results}

Table 3 Base Engine performance

\begin{tabular}{|c|c|c|c|c|c|c|}
\hline \multirow{2}{*}{ Speed } & \multicolumn{2}{|c|}{ Vol. Effi. (\%) } & \multicolumn{2}{c|}{ B.P. (KW) } & \multicolumn{2}{c|}{ B.T. (Nm) } \\
\cline { 2 - 7 } & Base & Simu. & Base & Simu. & Base & Simu. \\
\hline 1200 & 71.3 & 89 & 1.2 & 3.3 & 9.5 & 26.44 \\
\hline 1400 & 82 & 89.4 & 2 & 3.9 & 13.7 & 26.86 \\
\hline 1600 & 81 & 89.8 & 4.3 & 4.5 & 27.34 & 27.17 \\
\hline 1800 & 79.1 & 90.3 & 4.8 & 5.8 & 26.3 & 27.44 \\
\hline
\end{tabular}

The experimental engine performance as in table above is somewhat lower than that of the simulations results, that's may be because of the reduction in volumetric efficiency as compared to the simulated one. There are lot of factors contributing to the degradation in engine breathing such as minor leakages in the intake system, curvature \& surface roughness of the intake manifold, etc.

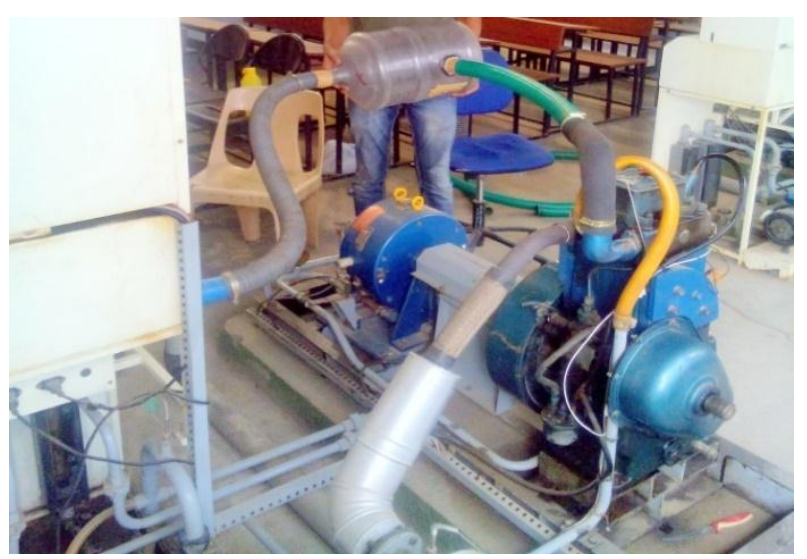

Fig. 6 Experimental rig

\subsection{Results after changing intake manifold length}

Table below shows the results obtained after changing the intake manifold length according to the engine speed as per the Chrysler Ram theory. Intake length is changed by gradually cutting the intake pipe to reduce its length as per the need. Table shows the comparative values of important performance parameters of engine with \& without the intake runner length variation.
There is considerable increase in brake torque \& power because of the effect of increasing the volumetric efficiency. Torque obtained at lower \& higher speed is increased which helps suggest one can vary the torque band as per the engine speed Improvement in brake torque helps to reduce fuel consumption.

Table 4 Engine performance enhancement by changing the intake length

\begin{tabular}{|c|c|c|c|c|c|c|c|}
\hline \multirow{2}{*}{ Speed } & \multirow{2}{*}{$\begin{array}{c}\text { Intake } \\
\text { Length } \\
(\mathrm{m})\end{array}$} & \multicolumn{2}{|c|}{ Vol. Effi. (\%) } & \multicolumn{2}{|c|}{ B.P. (KW) } & \multicolumn{2}{|c|}{ B.T. (Nm) } \\
\cline { 3 - 8 } & & Base & Expt & Base & Expt. & Base & Expt. \\
\hline 1200 & 1.98 & 71.3 & 95.5 & 1.2 & 2.0 & 9.5 & 14.4 \\
\hline 1400 & 1.7 & 82 & 87.2 & 2 & 4.0 & 13.7 & 26.71 \\
\hline 1600 & 1.49 & 81 & 86.1 & 4.3 & 5.2 & 27.34 & 30 \\
\hline 1800 & 1.19 & 79.1 & 84.6 & 4.8 & 5.6 & 26.3 & 32.5 \\
\hline
\end{tabular}

Figure below shows the increase in the volumetric efficiency over the base engine by using variable intake length (VIL). Minimum 5\% \& Maximum 25\% volumetric efficiency variation was obtained using VIL.
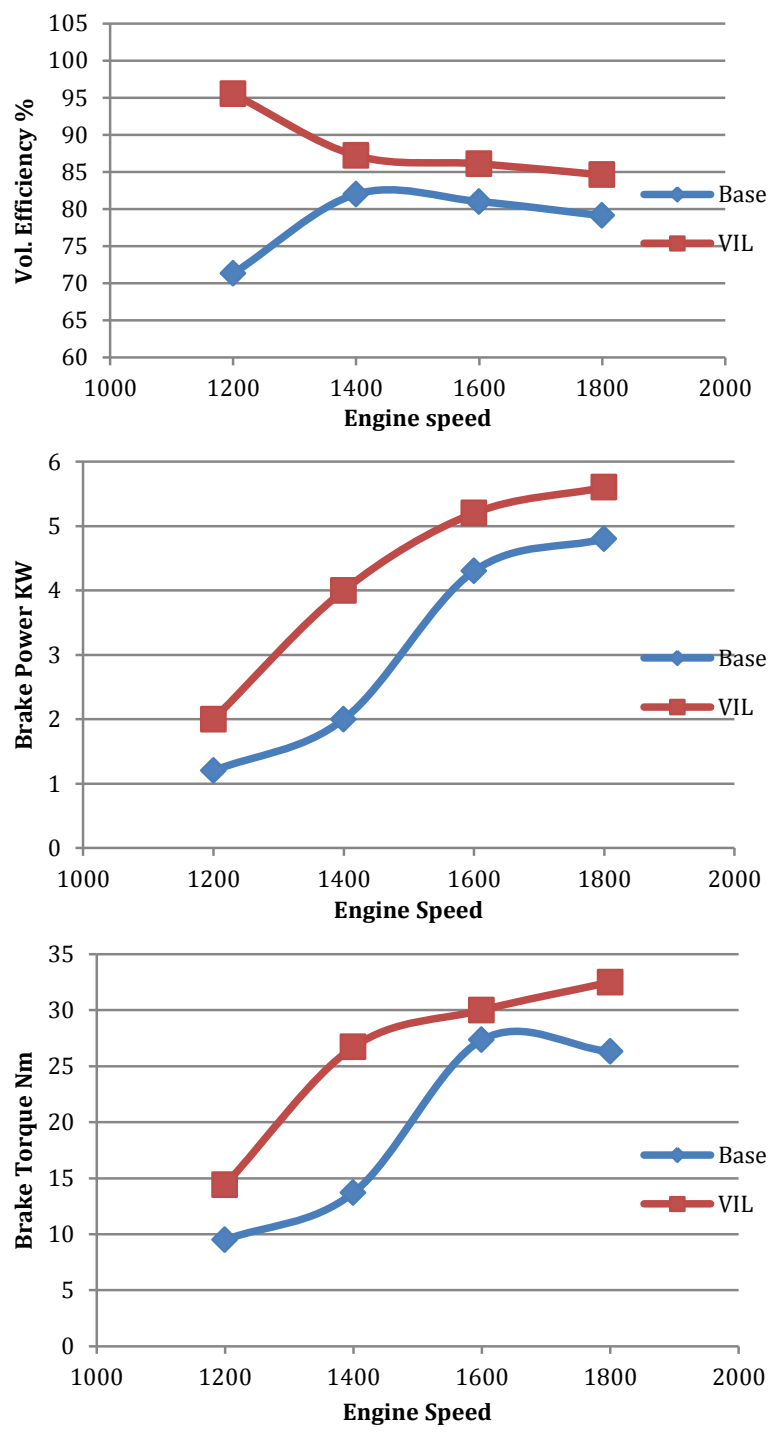

Fig. 7 Increase in BP, Brake Torque \& Vol. Efficiency 
From the Figure 07 it can be observed that there is significant increase in brake power and brake torque by varying the intake runner length as needed by engine speed. Intake runner length has to be decreased as engine speed goes on increasing because of the fact that the pressure waves created inside the intake manifold travels at the speed of sound which is almost constant at the STP conditions.

As the experimental engine was low speed diesel engine the required intake runner length was quite large \& accommodating such long intake was cumbersome task \& its fitment \& robustness during engine testing was quite difficult. Volumetric efficiency $\&$ brake torque obtained is somewhat lower compared to the simulation results using 1-D CFD code.

\section{Conclusions}

Based on the present experimental \& computational work it is concluded that the intake manifold geometry plays significant role in deciding engine's performance. Following are the some other important conclusion from the present work.

1) As the engine speed increases the length of intake manifold has to be reduced to achieve optimum engine performance.

2) Theoretical intake tuning methods closely predicts the intake length required to obtain maximum possible volumetric efficiency.

3) Significant improvement in volumetric efficiency, brake torque \& brake power is obtained using variable intake lengths.

4) Toque benefit is obtained in lower as well as higher RPM band.

5) Increase in volumetric efficiency, BP, \& brake torque at rated engine speed is near about $06 \%$, $17 \%$ \& $10 \%$, respectively.

\section{References}

M.A. Ceviz, - Intake plenum volume and its influence on the engine performance, cyclic variability and emissions|| Department of Mechanical Engineering, Faculty of Engineering, University of Ataturk, Erzurum 25240, Turkey,10 October 2006.

M.A. Ceviz, M. Akin, - Design of a new SI engine intake manifold with variable length plenum, Department of Mechanical Engineering, Faculty of Engineering, University of Atatürk, Erzurum 25240, Turkey, 21 March 2010.

Jensen Samuel, Prasad NS, and Kumarasamy Annamalai Effect of Variable Length Intake Manifold on a Turbocharged Multi-Cylinder Diesel Engine"'" SAE International, 2013-01-2756 Published 11/27/2013.

D N Malkhede, H Khalane - Maximizing Volumetric Efficiency of IC Engine through Intake Manifold Tuning, SAE International, 2015-01-1738 Published 04/14/2015.

Gilbert Sammut and Alex C. Alkidas, Relative Contributions of Intake and Exhaust Tuning on SI Engine Breathing - A Computational Study SAE Paper 2007-01-0492.

L. J. Hamilton, J. S. Cowart and J. J. Rozich, The Effects of Intake Geometry on SI Engine Performance SAE Paper 2009-01-0302.

Old ich Vítek and Miloš Polášek, Tuned Manifold Systems Application of 1-D Pipe Model SAE Paper 2002-01-0004.

James Taylor, David Gurney and Paul Freeland et. al. Intake Manifold Length Effects on Turbocharged Gasoline Downsizing Engine Performance and Fuel Economy SAE Paper, 2012-01-0714.

http://www.chrysler300club.com/uniq/allaboutrams/ramth eory.htm

Lotus Engine Simulation Users"s Manual, VERSION 5.05. Lotus cars Ltd., 2001.

Heywood JB. Internal combustion engine fundamentals. McGraw-Hill Inc.; 1988

Taehwan Kim - Variable Intake Manifold Development trend and technology, 2010 Shanghai PIM Conference.

http://www.autozine.org/technical_school/engine/intake_ex haust.html 